\title{
EXPANSIÓN URBANA EN CIUDADES DE LA REGIÓN DEL NORDESTE ARGENTINO
}

\author{
Prof. Aníbal Marcelo Mignone \\ Centro de Geociencias Aplicadas - UNNE \\ Departamento de Geografía - UNNE \\ 26 de abril de 2013
}

Presentado en:

Programa de Fortalecimiento Institucional de la Planificación Territorial Curso de Formación en Planificación y Ordenamiento del territorio para Agentes Gubernamentales. Año 2013.

Módulo 2 - Problemas Territoriales. Crecimiento Urbano, Infraestructura y Articulación territorial 
Esta presentación fue expuesta en el Programa de Fortalecimiento Institucional de la Planificación Territorial. Curso de Formación en Planificación y Ordenamiento del territorio para Agentes Gubernamentales. Año 2012. Módulo 2 - Problemas Territoriales: Crecimiento Urbano, Infraestructura y Articulación territorial. 26 de abril de 2013.

Objetivos del eje temático:

- Reconocer los principales factores que impulsan la configuración actual de las ciudades de la región del Nordeste Argentino

- Analizar los procesos de crecimiento y expansión en las capitales provinciales del NEA.

- Reflexionar sobre la incidencia de las políticas públicas en las ciudades de la región.

Título:

\section{EXPANSIÓN URBANA EN CIUDADES DE LA REGIÓN DEL NORDESTE ARGENTINO}

\section{Autor:}

Prof. Aníbal Marcelo Mignone, animarmig@hotmail.com 


\section{SUBSISTEMA URBANO DEL NEA}

$\checkmark$ Presenta una morfología de tipo anular-lineal.

$\checkmark \quad$ Es lineal por los ejes:

- Ríos Paraná-Paraguay - ruta Nac. № 11

- Ruta Nac. № 16, Ruta Nac. № 89 y Ruta Nac. № 12

- Río Uruguay - Ruta Nac. № 14

$\checkmark \quad$ Es anular al observar una distribución en anillos alrededor del núcleo bipolar Resistencia- Corrientes.

$\checkmark$ Posadas escapa a esta distribución.

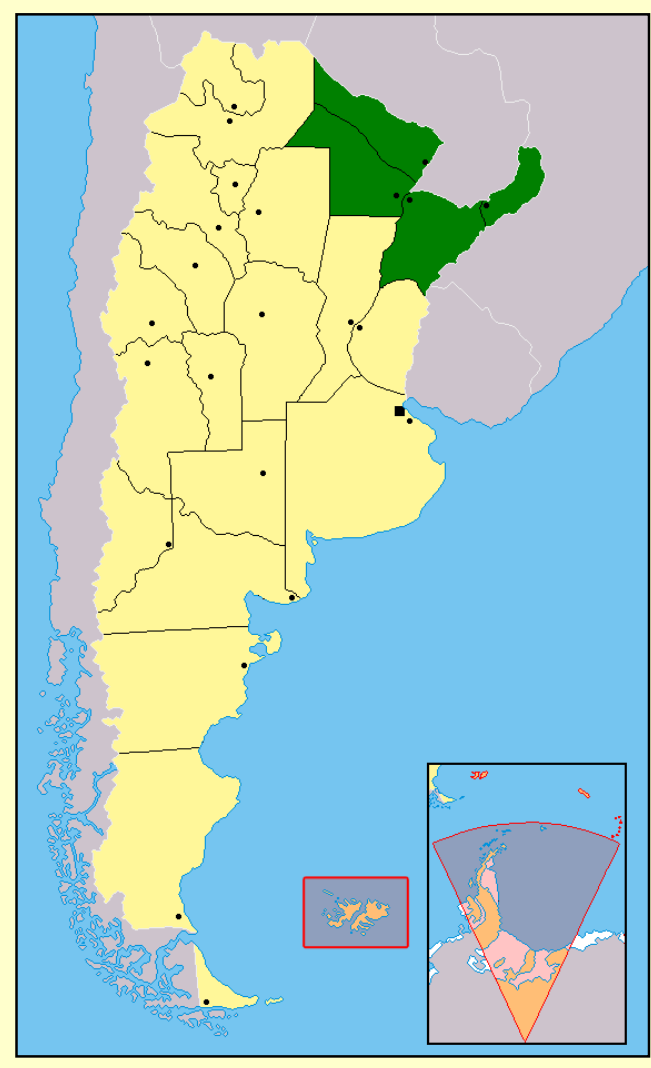

Fuente: Roccatagliata y Beguiristain,1992

Publicado en formato digital: Prof. Aníbal Marcelo Mignone. EXPANSIÓN URBANA EN CIUDADES DE LA REGIÓN DEL NORDESTE ARGENTINO. Revista Geográfica Digital. IGUNNE. Facultad de Humanidades. UNNE. Año 14. № 27. Enero - Junio 2017. Resistencia, Chaco. En: 


\section{CARACTERÍSTICAS CAPITALES DEL NEA}

- Las cuatro ciudades se consideran Aglomeraciones de Tamaño Intermedio o ATls (Vapñarsky y Gorojosky,1990).

- Desde la década de 1960, son el grupo de ciudades que más han tenido un crecimiento acelerado de su población y de los ejidos urbanos.

- Presentan una gran concentración de la población con respecto al total provincial.
- La conformación de las ciudades fue resultado de tres procesos (Reese, 1997):

- Expansión de la mancha urbana

- Consolidación

- Densificación

- La producción en la ciudad ha operado de la siguiente manera: "Primero ocupo, después urbanizo"

- Cambios en la delimitación del ejido urbano (Alberto, 2009), incide en:

- Tasación de impuestos y servicios.

- Ordenamiento urbano y los usos del suelo.

- Valoración inmobiliaria y la especulación sobre la evaluación monetaria de las tierras, especialmente las comprendidas en los ejes de expansión de las ciudades. 
Limitaciones en el crecimiento de la mancha urbana

- Localización de los aeropuertos internacionales o aeródromos locales.

- Existencia de terrenos cuya jurisdicción pertenecen al Ejército Argentino.

- Restricciones hídricas, ya que las cuatro ciudades se encuentran atravesadas por ríos, arroyos o lagunas que obstaculizan el asentamiento porque son terrenos bajos e inundables.

- Parte de los cuerpos de agua han sido entubados, canalizados o sepultados, lo que llevo a alteraciones por el delicado equilibrio natural de los cursos.
Problemas por el acelerado crecimiento

- Déficit en infraestructura y equipamiento de servicios básicos.

- Dificultad en la accesibilidad de la población a los medios de transportes públicos.

- Construcción de barrios planificados a largas distancias y en paquetes (densificación de estos complejos).

- Valorización diferencial en el precio de los terrenos, de acuerdo a la provisión de servicios, a la distancia del área central o a las vías de circulación. 


\section{La localización de las capitales del NEA}

- El sitio es desfavorable para los aglomerados del Gran Resistencia y Formosa, porque se localizan sobre los valles de inundación de los ríos Paraná y Paraguay, respectivamente.

- En menor grado, en Corrientes las limitaciones aparecen en los extremos noreste y sureste, mientras que Posadas se ve afectado por el Paraná en el sector oriental de la misma, y por los arroyos interiores.

- En épocas de crecientes máximas, los municipios emplazados total o parcialmente en las terrazas de inundación, se inundan causando problemas muy serios en la población.
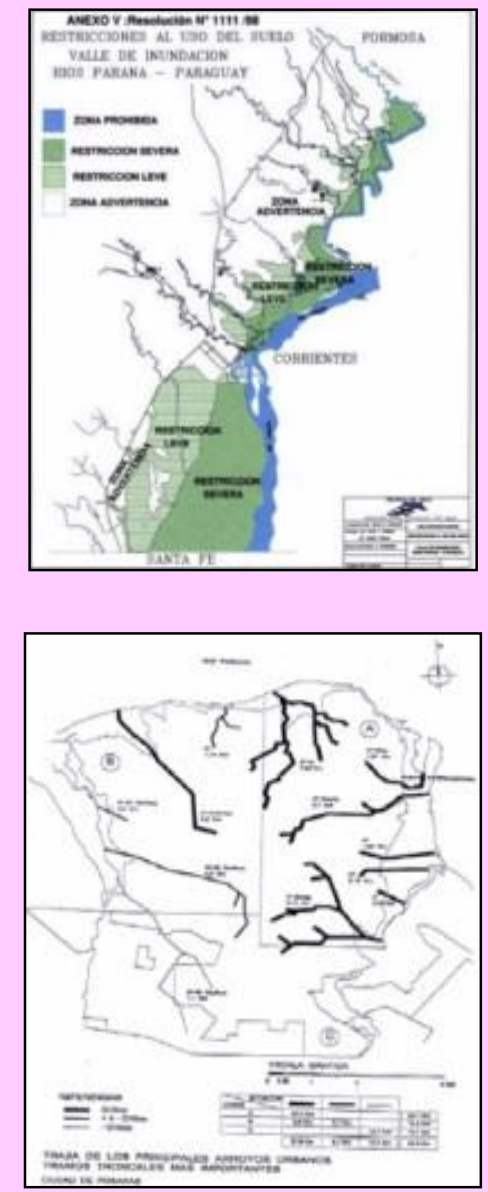

Fuente: Alberto y Schneider, 2009; "Restricciones al uso del suelo del Gran Resistencia. Anexo VI: Resolución 1111/98” según Área de Estudios Básicos de la Administración Provincial del Agua (APA). Agosto 1998.

Municipalidad de Posadas. 2008. Planificación estratégica territorial 


\section{LA PERIFERIA URBANA: LO URBANO Y LO RURAL}

- Es difícil identificar los límites entre el ámbito natural no urbanizado y el espacio urbanizado.

- En las periferias urbanas aparecen multitud de nuevos usos que no se pueden calificar propiamente de urbanos ni exactamente de rurales.

- Periurbanización: invernaderos y quintas semiurbanizadas, campus universitarios, almacenes mayoristas, clubes, cementerios parques.

- Rururbanización: industrias aisladas, centros de investigación, etc., en ámbitos rurales.

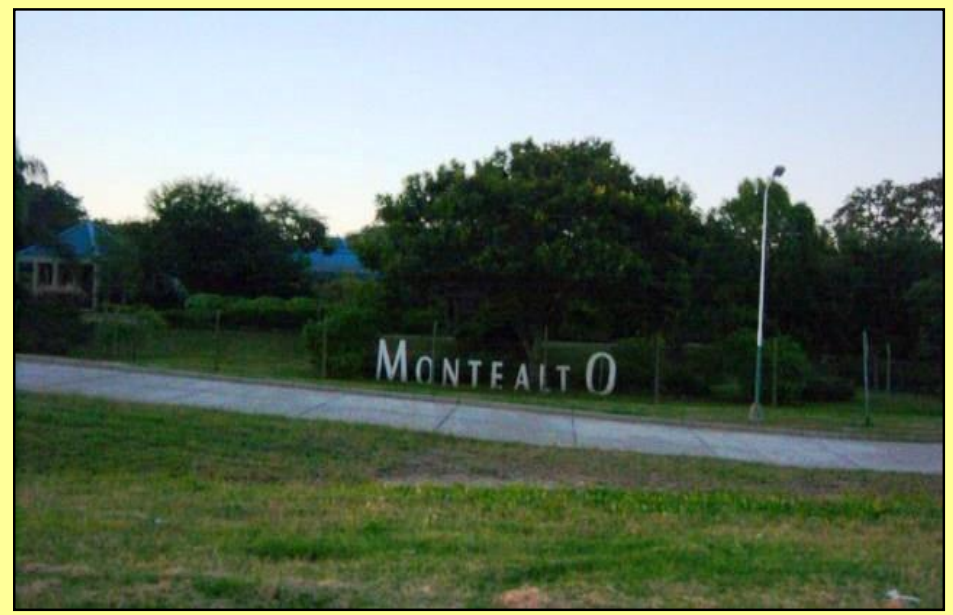

Fuente: Alberto, 2009

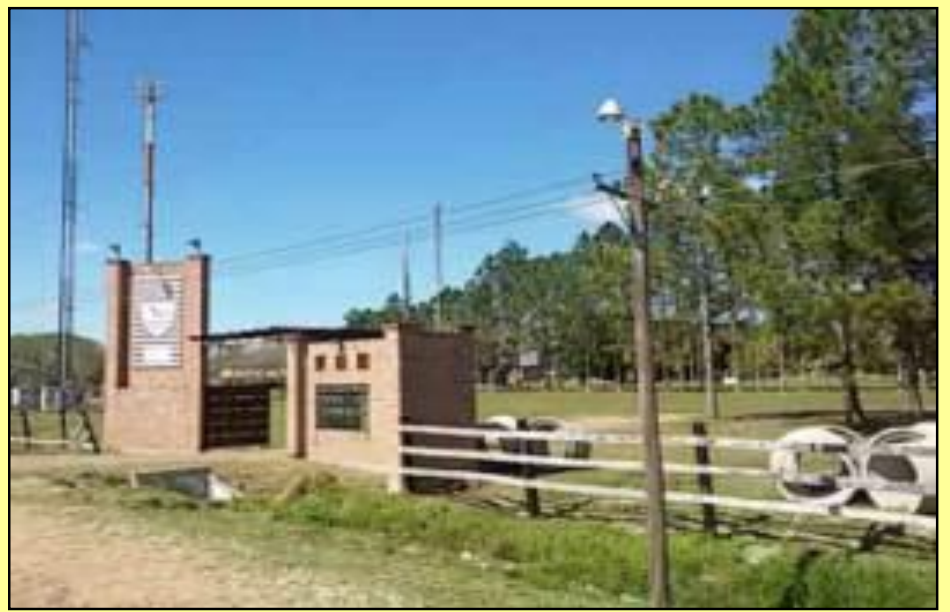

Publicado en formato digital: Prof. Aníbal Marcelo Mignone. EXPANSIÓN URBANA EN CIUDADES DE LA REGIÓN DEL NORDESTE ARGENTINO. Revista Geográfica Digital. IGUNNE. Facultad de Humanidades. UNNE. Año 14. № 27. Enero - Junio 2017. Resistencia, Chaco. En: 


\section{LA PERIFERIA URBANA EN LAS CAPITALES DEL NEA}

El avance de la mancha urbana hacia la periferia se da por implantación:

- Comercios mayoristas

- Depósitos de los negocios localizados en "el centro de la ciudad"

- Radicación de industrias

- Incipientes áreas residenciales:

- Por el flujo de población procedente del interior de cada provincia

- La creación de barrios planificados y barrios cerrados

- Los asentamientos informales 


\section{Formas de crecimiento de las capitales: caso Gran Resistencia}

- Extensión de la urbanización por contigüidad

- Urbanización por paquetes

- Urbanización marginal o asentamientos espontáneos en parcelas no urbanizadas

- Urbanización tradicional en enclaves topográficos.

- Urbanización intersticial 
Extensión de la urbanización por contigüidad

\section{Urbanización por paquetes}

- Extensión de la ciudad mediante la urbanización progresiva de sectores contiguos a las áreas ya urbanizadas.

- A partir de la subdivisión del suelo y de la extensión de determinadas infraestructuras básicas, se produce la ocupación progresiva aunque no secuencial de los lotes.

- La construcción de las viviendas es un proceso individual y de inversión privada.
- La denominación obedece a una serie de características derivadas de su modalidad de ejecución, de su tipo de emplazamiento y del tipo de relación con su entorno inmediato.

- No requiere la proximidad de áreas consolidadas para extender y prolongar vías e infraestructuras sino las conexiones a las redes de infraestructura y la comunicación básica con el resto de la ciudad. 
Urbanización marginal o asentamientos espontáneos en parcelas no urbanizadas

- Inician el proceso de urbanización con la construcción precaria de una vivienda mínima y la subdivisión irregular del suelo ocupado.

- En áreas con problemas ambientales.

\section{Urbanización tradicional en enclaves topográficos}

- Se trata de urbanizaciones que reproducen la trama primigenia de la ciudad allí donde el suelo lo permite, interrumpiéndose frente a las lagunas o el rio, sin respetar necesariamente las líneas de ribera.

- La idea de enclave está dada por la presencia de los límites físicos.

- El condicionamiento topográfico determina la escasa accesibilidad y la seria dificultad que en general tienen estas urbanizaciones para dotarlas de infraestructuras y servicios 


\section{Urbanización intersticial}

\section{- Las urbanizaciones se realizan en áreas libres pero que ya se encuentran rodeadas total 0 parcialmente por edificaciones.}

Diversas formas de ocupación:

- La prolongación de la ciudad tradicional

- Construcción de barrios de viviendas

- Nuevas ocupaciones informales 


\section{Problemas ambientales por la expansión de las ciudades}

- Deforestación

- Desbroce de pastizales

- Rellenos sanitarios

- Obras de infraestructura

- Trazado de las calles

- $\quad$ Red de servicios públicos

- Instalación de desagües clandestinos

- Acumulación de residuos a cielo abierto

- Proximidad de las lagunas de oxidación

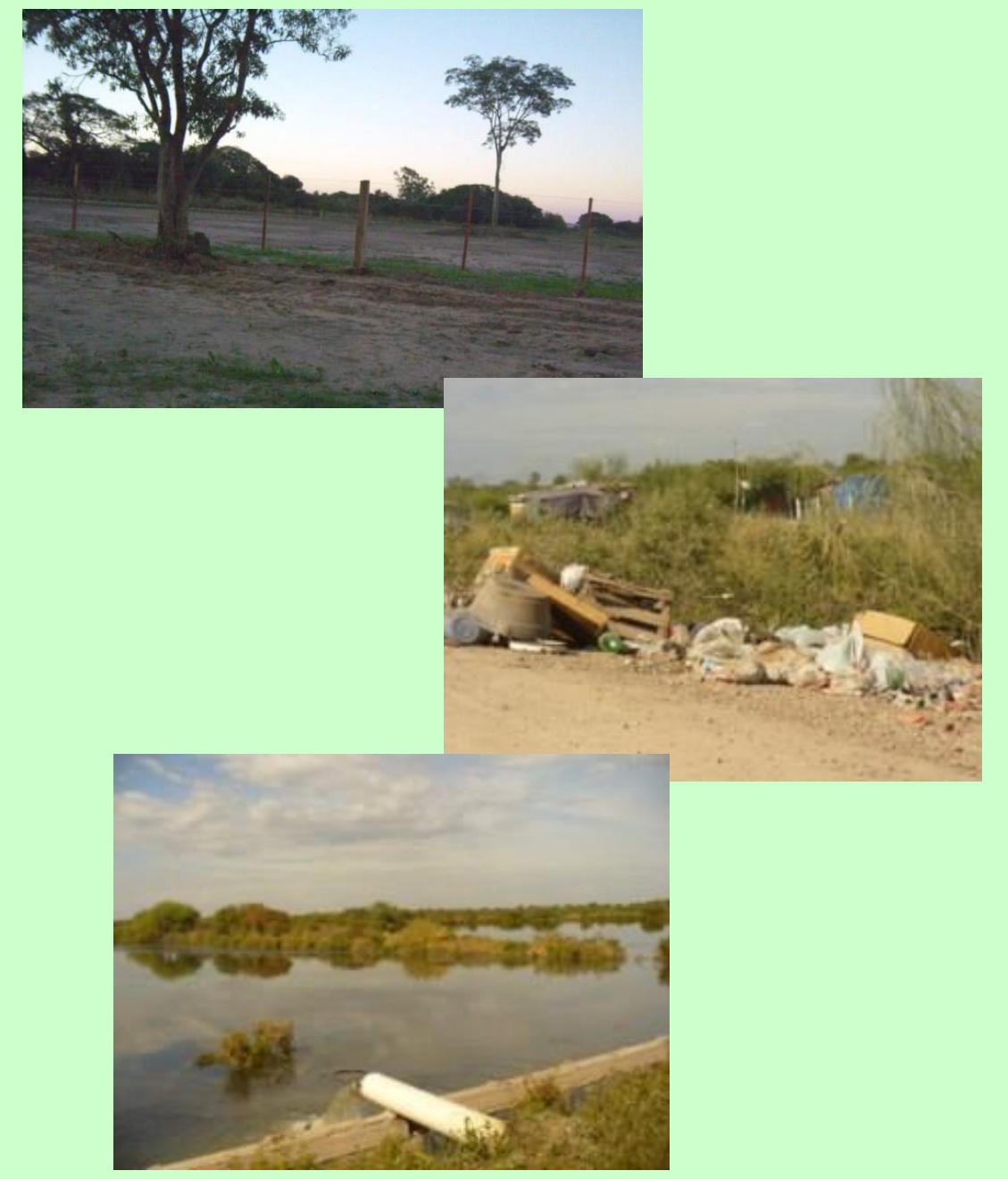

Fuente: Alberto, 2009; Alberto y Schneider, 2008

Publicado en formato digital: Prof. Aníbal Marcelo Mignone. EXPANSIÓN URBANA EN CIUDADES DE LA REGIÓN DEL NORDESTE ARGENTINO. Revista

Geográfica Digital. IGUNNE. Facultad de Humanidades. UNNE. Año 14. № 27. Enero - Junio 2017. Resistencia, Chaco. En:

http://hum.unne.edu.ar/revistas/geoweb/default.htm 


\title{
PRINCIPALES MODALIDADES DE OCUPACIÓN RESIDENCIAL EN LAS CAPITALES DEL NEA
}

\author{
+ Asentamientos informales
}

+ Complejos habitacionales

+ Barrios cerrados

+ Edificios en torre 


\section{LOS ASENTAMIENTOS INFORMALES}

- Ocupación ilegal de la propiedad pública o privada.

- Compra de terrenos sin la correspondiente transferencia de propiedad.

- Construcción (y la consolidación posterior) sin permiso de construcción.

- Incumplimiento de normas de construcción.

\section{Problemas de la población asentada}

- No cuentan con un título de propiedad (capital físico).

- No poseer el título del terreno, provoca el miedo frente al posible desalojo.

- Dificultad para acceder a un créditos públicos en condiciones favorables para la construcción y mejoras de viviendas.

Fuente: Mignone, 2000, 2003, 2005; Barreto y Sánchez, 2000

Publicado en formato digital: Prof. Aníbal Marcelo Mignone. EXPANSIÓN URBANA EN CIUDADES DE LA REGIÓN DEL NORDESTE ARGENTINO. Revista Geográfica Digital. IGUNNE. Facultad de Humanidades. UNNE. Año 14. № 27. Enero - Junio 2017. Resistencia, Chaco. En: 


\section{LOS ASENTAMIENTOS INFORMALES}

- Fundamentalmente en la periferia de la ciudad.

- Con población joven o adulta-joven, por la facilidad para migrar del interior o relocalizarse dentro de la ciudad.

- Se tratan de hogares nucleares, compuestos por padres e hijos.

- Conforman los ghettos o bolsones de pobreza.

- En terrenos bajos e inundables próximos a los ríos o arroyos.

- En lugares dónde no ha llegado la infraestructura de los servicios, precisamente en terrenos por el momento no urbanizados y de bajo costo.

- Proximidad a los barrios planificados, o sectores con altos ingresos.

- Condiciones de accesibilidad al centro de la ciudad.
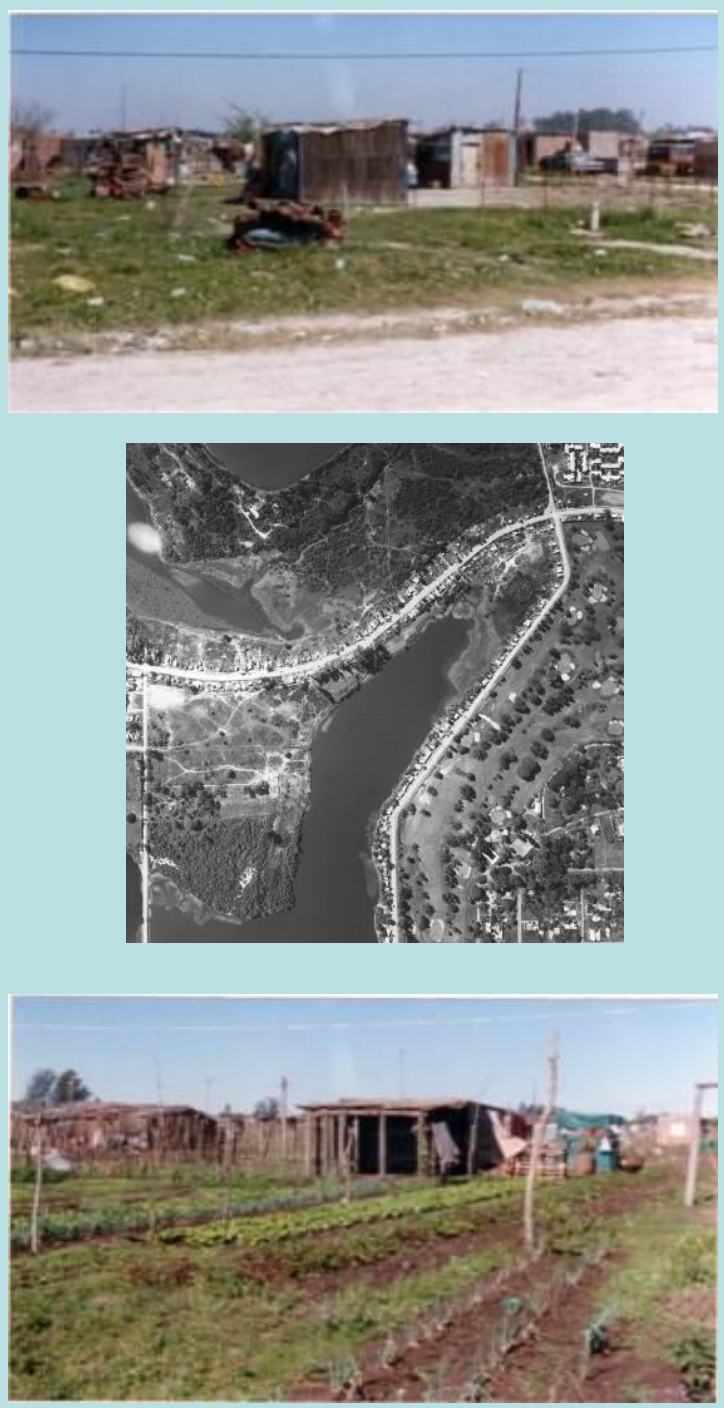

Fuente: Mignone, 2000, 2003, 2005

Publicado en formato digital: Prof. Aníbal Marcelo Mignone. EXPANSIÓN URBANA EN CIUDADES DE LA REGIÓN DEL NORDESTE ARGENTINO. Revista Geográfica Digital. IGUNNE. Facultad de Humanidades. UNNE. Año 14. № 27. Enero - Junio 2017. Resistencia, Chaco. En: 
Las ocupaciones ilegales de tierras por lo general no respetan las reglamentaciones oficiales de uso del suelo y manifiestan casi siempre un plano muy irregular.

\section{Dificultades:}

La regulación dominial

\section{El trazado de calles/caminos}

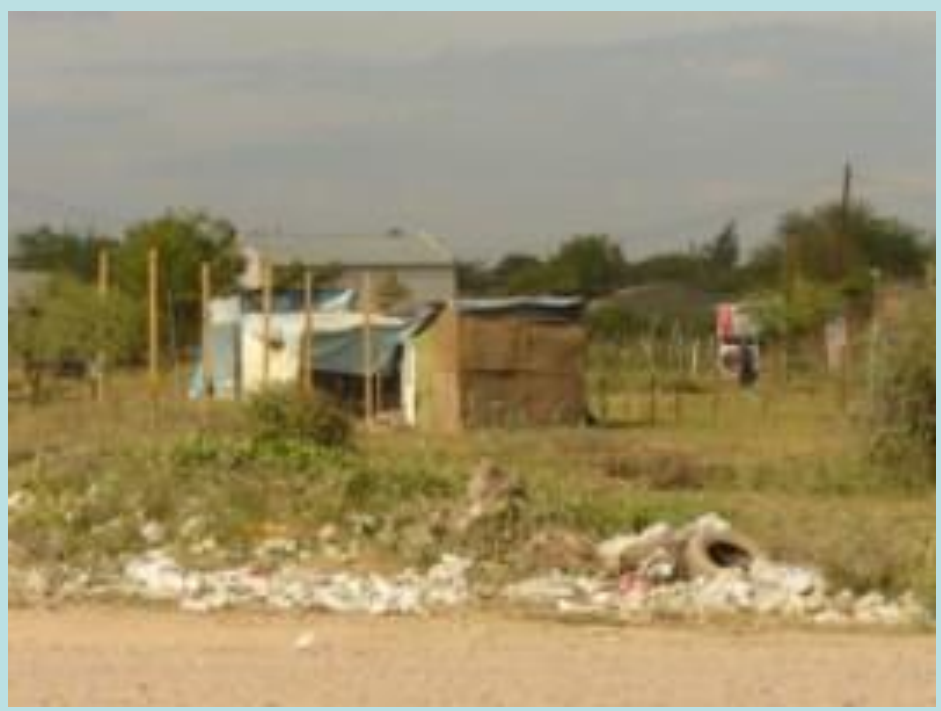

Procesos de relocalización de ser necesario y no siempre efectivos

Problemas financieros y sociales de la población

Fuente: Mignone, 2000, 2003, 2005; Alcalá, 2007; Barreto, 2002

Publicado en formato digital: Prof. Aníbal Marcelo Mignone. EXPANSIÓN URBANA EN CIUDADES DE LA REGIÓN DEL NORDESTE ARGENTINO. Revista Geográfica Digital. IGUNNE. Facultad de Humanidades. UNNE. Año 14. № 27. Enero - Junio 2017. Resistencia, Chaco. En: 


\section{LOS BARRIOS PLANIFICADOS EN LAS CAPITALES DEL NEA}

\section{Antes de los '90}

- Viviendas construidas bajo la forma de conjuntos habitacionales localizados en el borde periférico de las ciudades.

- Grupos de viviendas de $\mathbf{2 0 0}$ hasta 1000 unidades, agrupadas en pabellones de tres o cuatro niveles, con espacios verdes comunes, infraestructura básica y vías de comunicación .

- Extendieron el ejido de la ciudad valorizando nuevas tierras urbanizables.

- La política habitacional priorizó la rentabilidad económica de las empresas constructoras más que la calidad de vida de sus habitantes.

\section{En los ‘90 y hasta la actualidad}

- Unidades construidas como viviendas individuales no siempre en el borde periférico de las ciudades.

- Grupos de viviendas de 100 a 200 unidades, de una sola planta, con espacios verde comunes, provisión de infraestructura básica y vías de comunicación.

- Se realizan convenios donde intervienen los gremios y asociaciones de diferentes sectores.

- La política habitacional prioriza la calidad de vida de los habitantes, se exige un cierto pago del valor total de la obra. 


\section{BARRIOS PLANIFICADOS: CIUDAD DE RESISTENCIA}

ANTES DE 1990
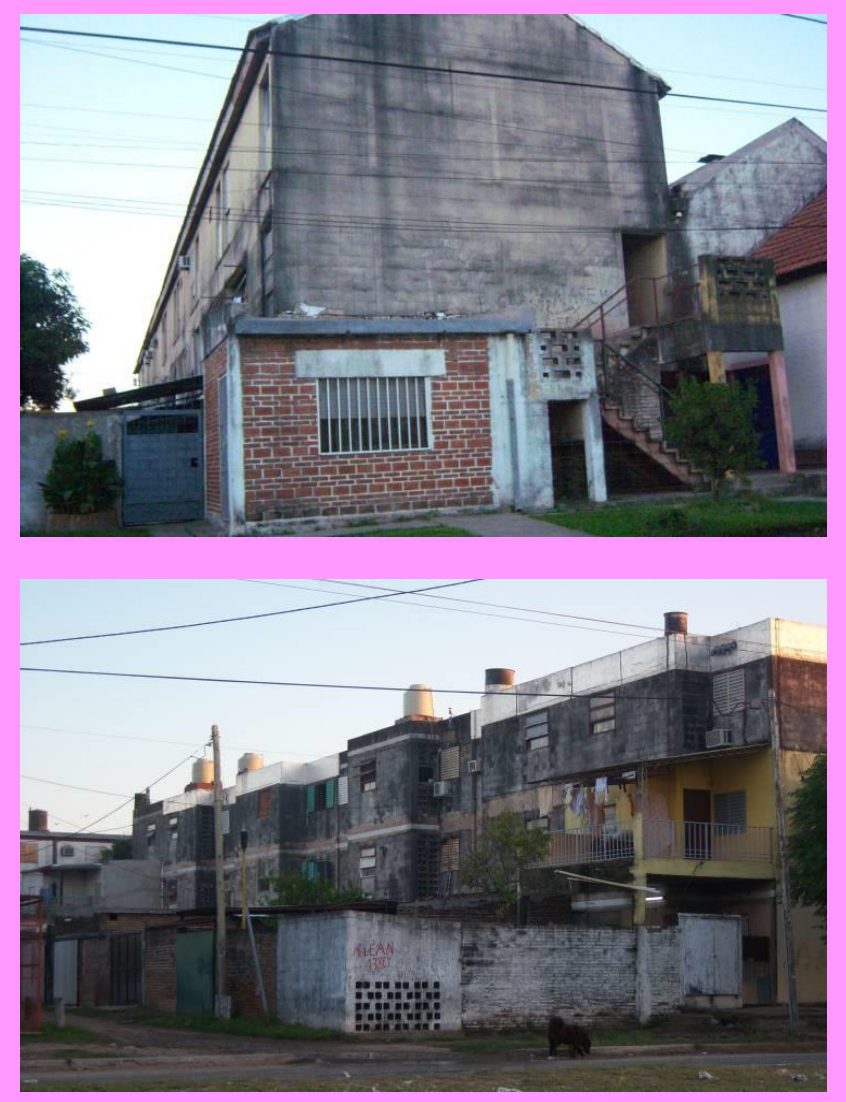

DESPUÉS DE 1990
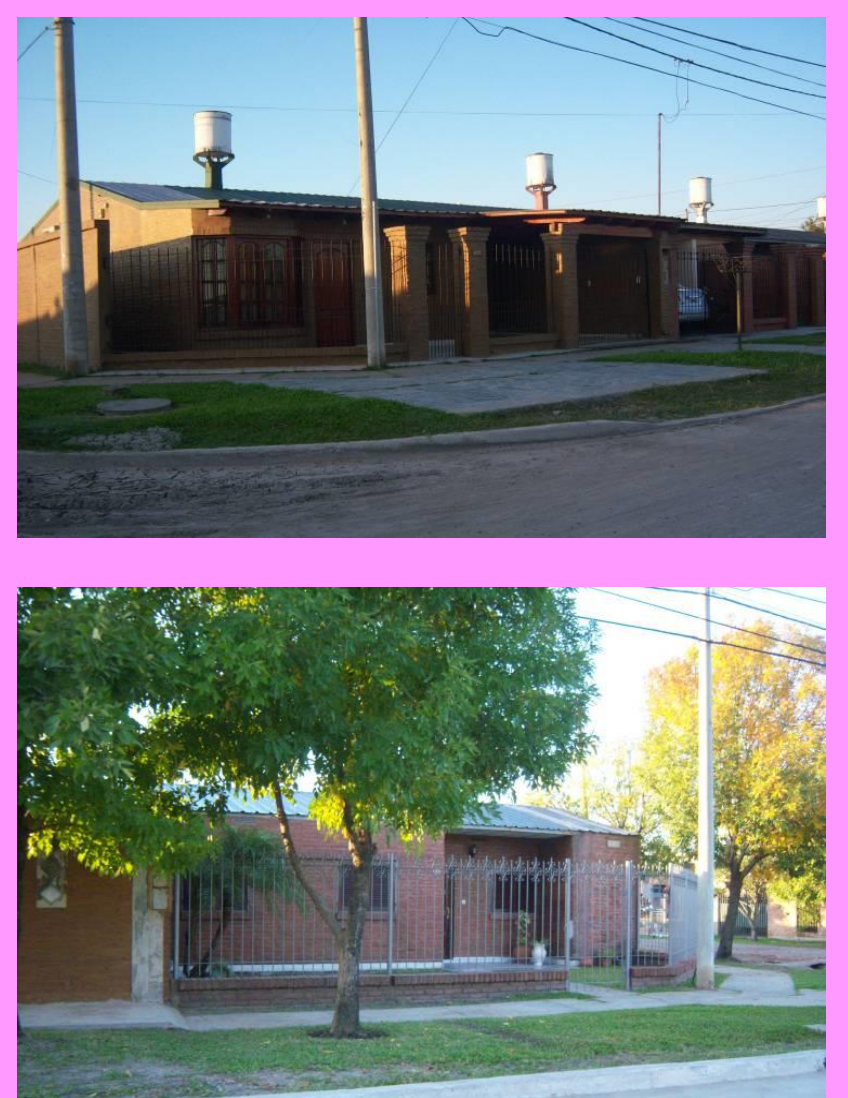

Fuente: Imágenes tomadas por el autor, 2012.

Publicado en formato digital: Prof. Aníbal Marcelo Mignone. EXPANSIÓN URBANA EN CIUDADES DE LA REGIÓN DEL NORDESTE ARGENTINO. Revista Geográfica Digital. IGUNNE. Facultad de Humanidades. UNNE. Año 14. № 27. Enero - Junio 2017. Resistencia, Chaco. En:

http://hum.unne.edu.ar/revistas/geoweb/default.htm 


\section{LOS BARRIOS ESTATALES}

- Barrios construidos (paquetes) unidos a una vía de circulación. Se da un crecimiento por "saltos".

- Se transforman en áreas segregadas por la planificación habitacional.

- En los intersticios se localizan los "asentamientos informales"

- Problemas en el acceso de las vías. Las calles sin pavimentar no son transitadas por las líneas de colectivos en los días de lluvias.

Fuente: Alcalá, 2007; Mignone 2000; Barreto, 2002

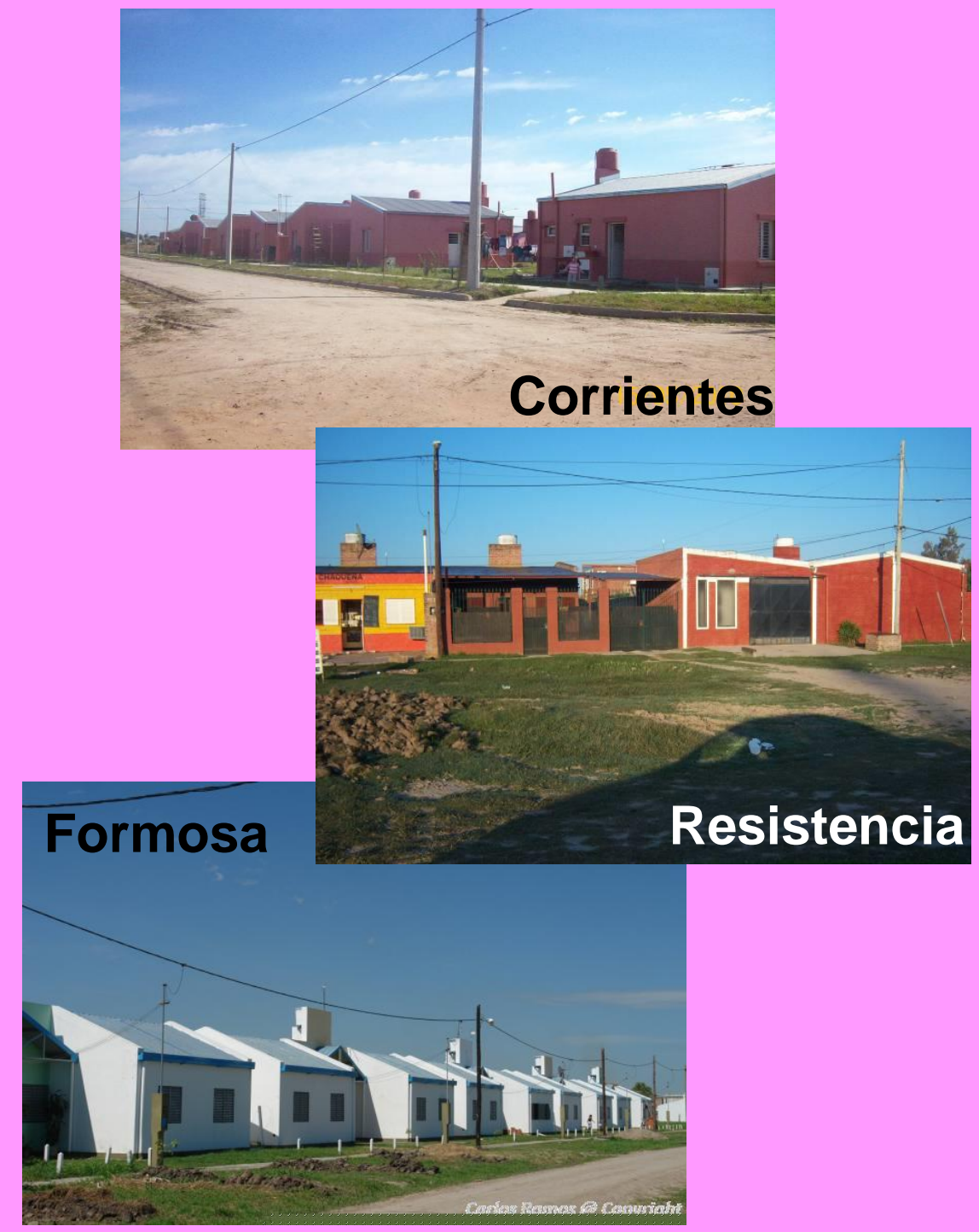

Publicado en formato digital: Prof. Aníbal Marcelo Mignone. EXPANSIÓN URBANA EN CIUDADES DE LA REGIÓN DEL NORDESTE ARGENTINO. Revista Geográfica Digital. IGUNNE. Facultad de Humanidades. UNNE. Año 14. № 27. Enero - Junio 2017. Resistencia, Chaco. En: 


\section{LOS BARRIOS CERRADOS}

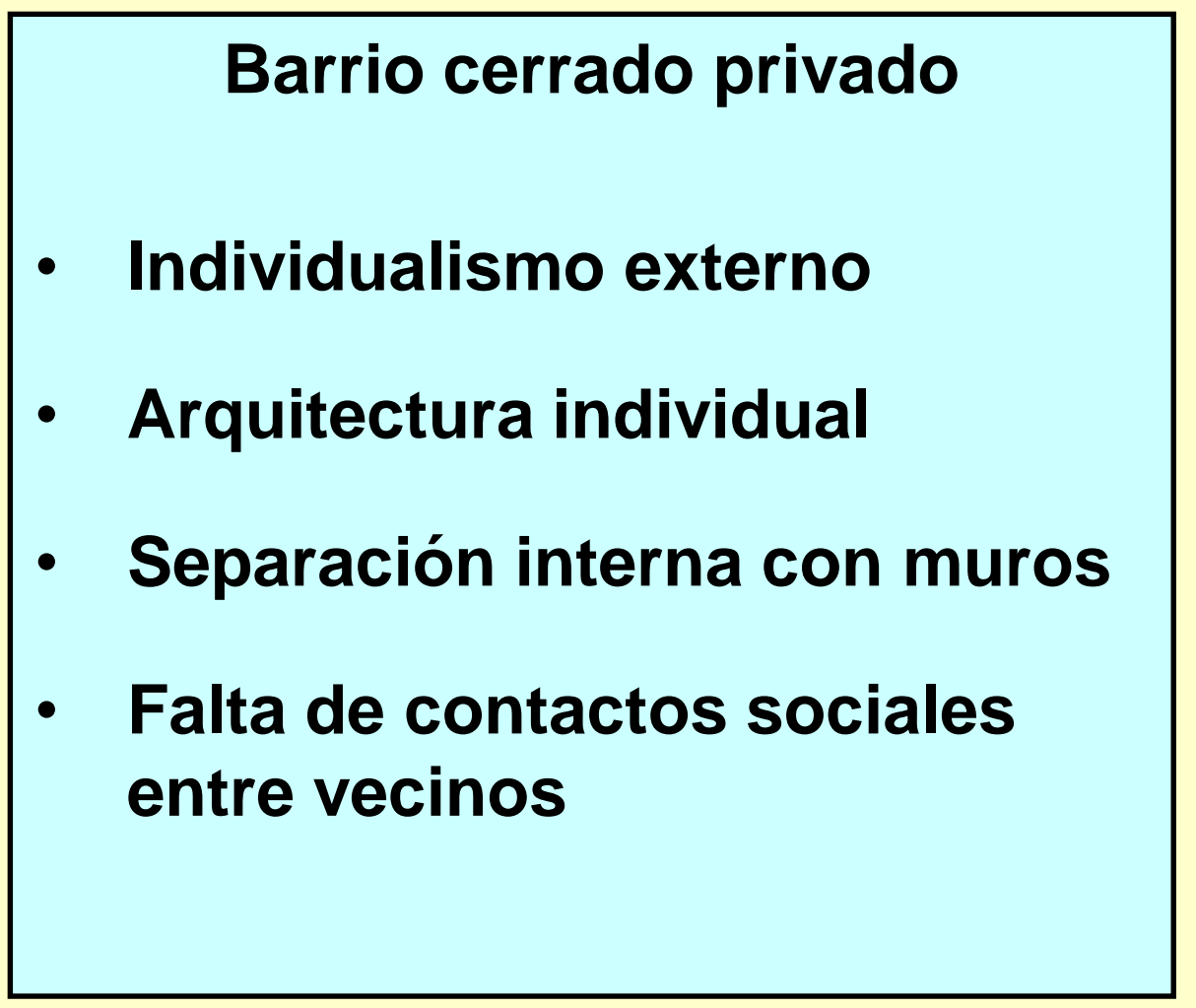

\section{Barrio cerrado de clase media}

- Mayor diversidad en la composición social.

- Arquitectura estandarizada

- Precios moderados

- Mayor contacto social entre vecinos

Fuente: Borsdorf, 2003 


\section{LOS ENCLAVES DE RIQUEZA: Barrios cerrados en Resistencia}

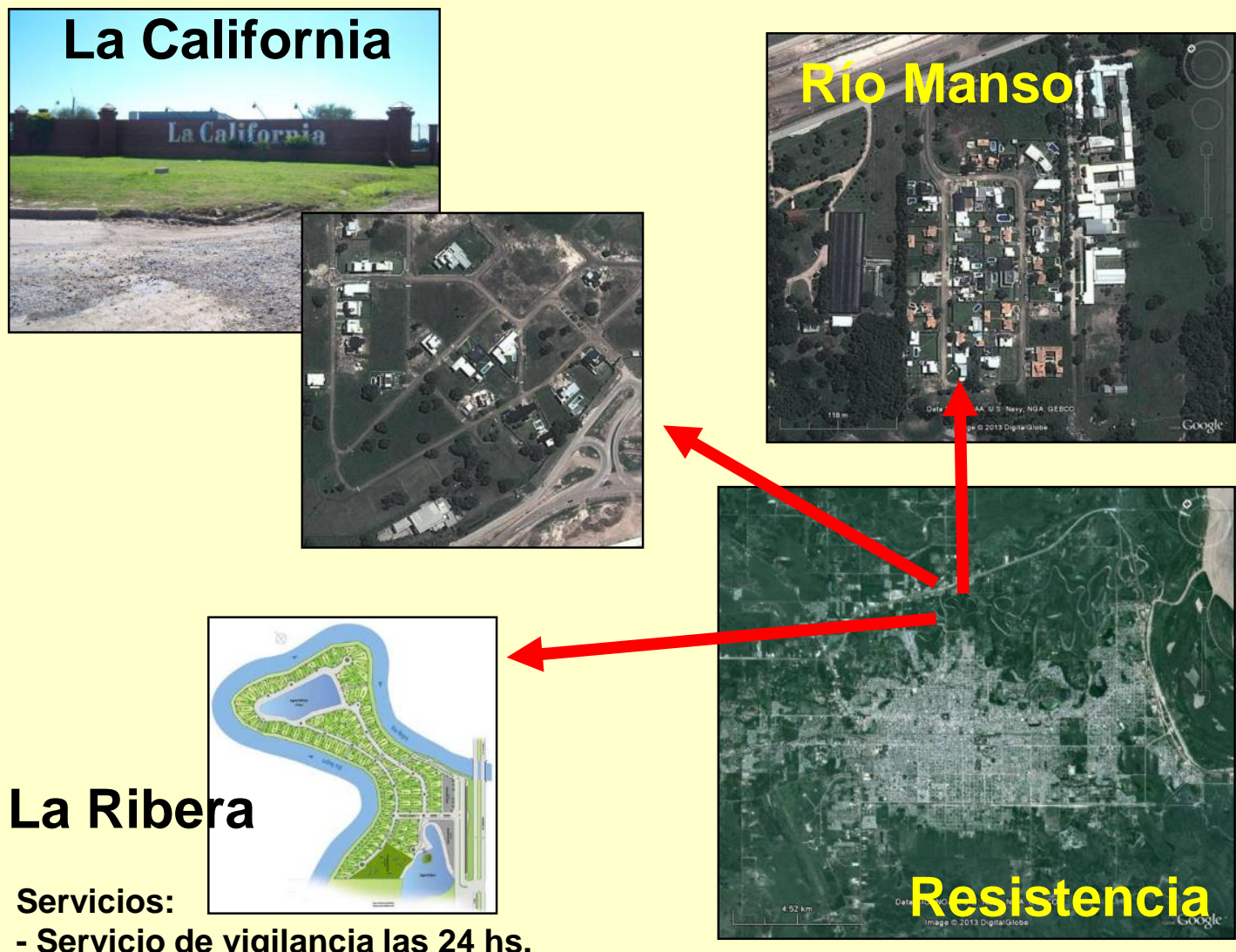

- Servicio de vigilancia las 24 hs.

- Red de luz y cloacas.

- Agua corriente presurizada.

- Luz de emergencia en calles, circuito peatonal y bici-senda.

- Servicio de mantenimiento de espacios verdes, agua, luz y cloacas.

\section{Crecimiento por paquete}

\section{Localizados en las áreas} de expansión de la ciudad.

\section{Próximos a una vía} principal de circulación.

\section{Población de clase} media-alta y alta.

Fuente: Borsdorf, 2003; Alcalá, 2007

Publicado en formato digital: Prof. Aníbal Marcelo Mignone. EXPANSIÓN URBANA EN CIUDADES DE LA REGIÓN DEL NORDESTE ARGENTINO. Revista Geográfica Digital. IGUNNE. Facultad de Humanidades. UNNE. Año 14. № 27. Enero - Junio 2017. Resistencia, Chaco. En: 


\section{EDIFICIOS EN TORRE}

- Gran desarrollo desde la década de 1990.

- Fundamentalmente inversión privada.

- Para población de clase media y mediaalta.

- Algunos son construidos para población de determinados organismos públicos.

- Densificación en zonas céntricas, siempre cercano a una vía de circulación rápida.

- Problemas: provisión de agua, capacidad de desagote cloacal, vorticidad del viento.

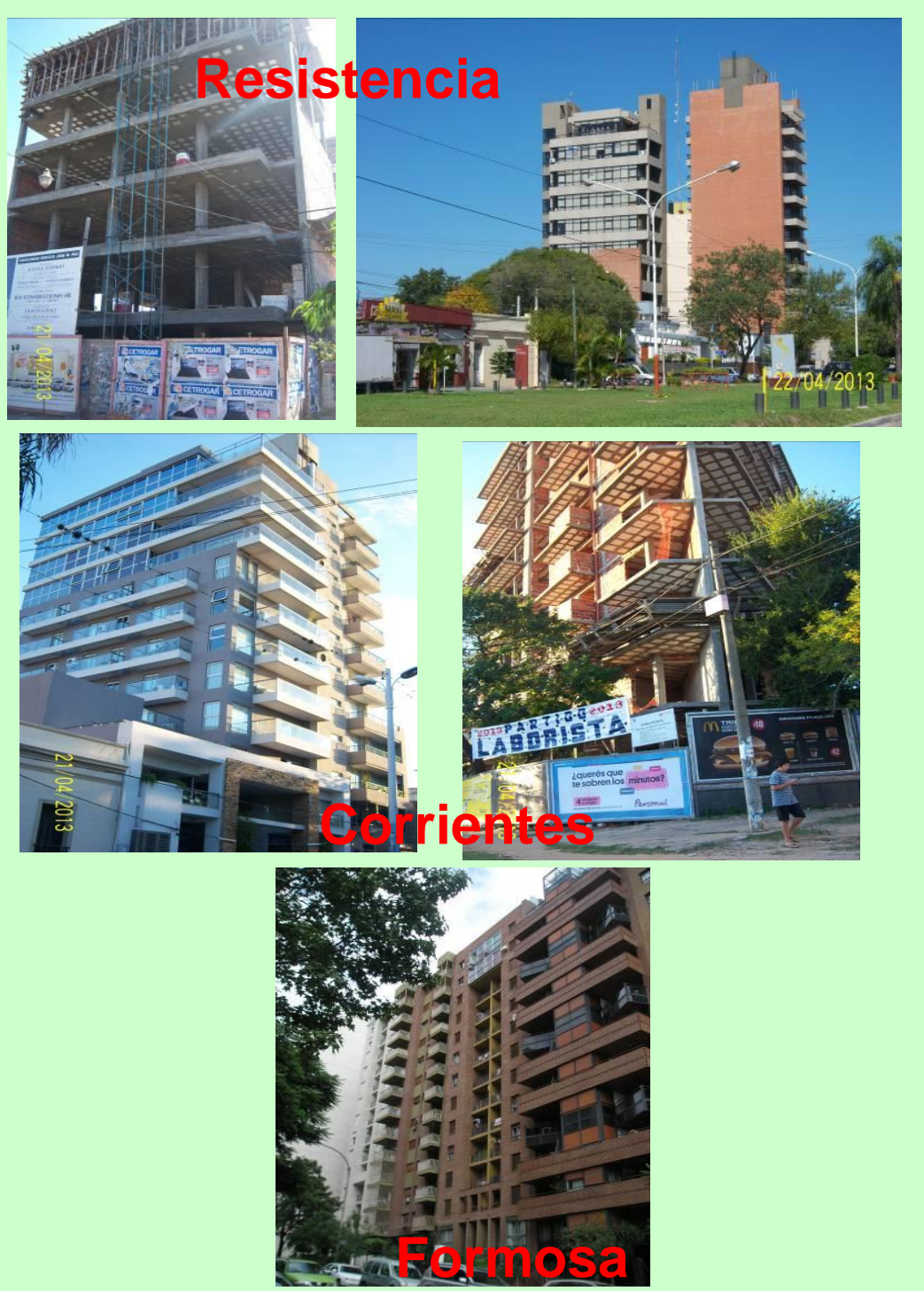

Publicado en formato digital: Prof. Aníbal Marcelo Mignone. EXPANSIÓN URBANA EN CIUDADES DE LA REGIÓN DEL NORDESTE ARGENTINO. Revista Geográfica Digital. IGUNNE. Facultad de Humanidades. UNNE. Año 14. № 27. Enero - Junio 2017. Resistencia, Chaco. En: 


\section{LAS TIERRAS VACANTES Y LOS LOTEOS DE TIERRAS}

* Los vacíos urbanos son el resultado del funcionamiento de tierras con escasas regulaciones estatales.

* Los diferentes agentes que actúan en el mismo, se apropian de las rentas generadas por su existencia (Clivchevsky, 1999)

* Planes de loteos en áreas internas de la ciudad.

* En los intersticios, son loteados los terrenos por inmobiliarias

* La ocupación también se produce en la periferia de las ciudades.

-Modificación del medio natural.

•Zonas con riesgo hídricos.

* Ocupaciones en el marco del mercado formal inmobiliario.
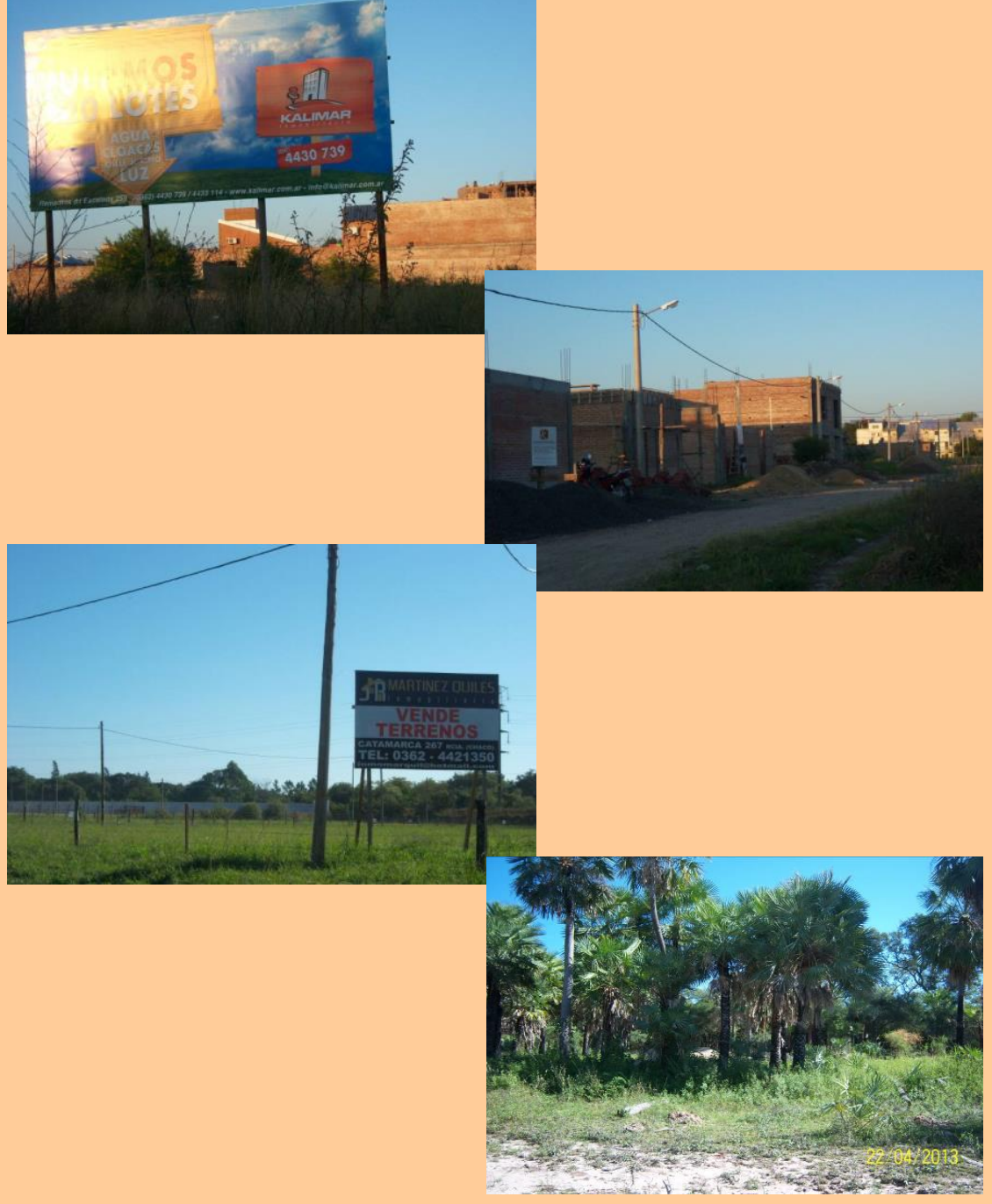

Publicado en formato digital: Prof. Aníbal Marcelo Mignone. EXPANSIÓN URBANA EN CIUDADES DE LA REGIÓN DEL NORDESTE ARGENTINO. Revista Geográfica Digital. IGUNNE. Facultad de Humanidades. UNNE. Año 14. № 27. Enero - Junio 2017. Resistencia, Chaco. En: 


\section{LOS PLANES DE ORDENAMIENTO: el caso de la ciudad de Corrientes}

\section{Plan Regulador Roca (1952)}

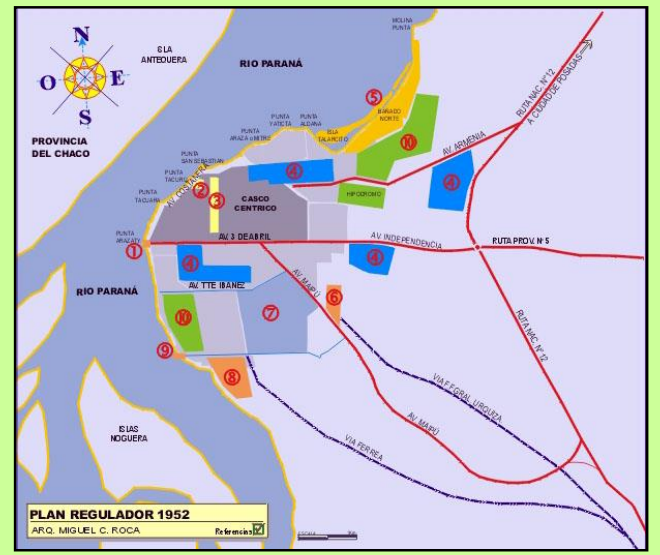

Plan de Diagnóstico Urbano de la Provincia de Corrientes (1988)

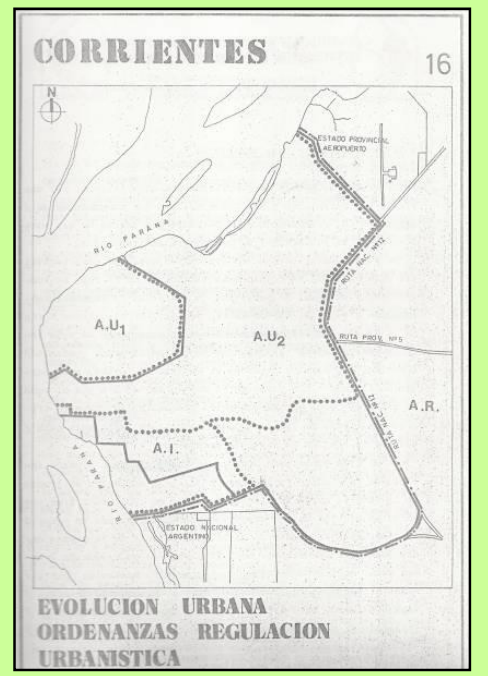

Plan Consejo Federal de inversiones (1978)

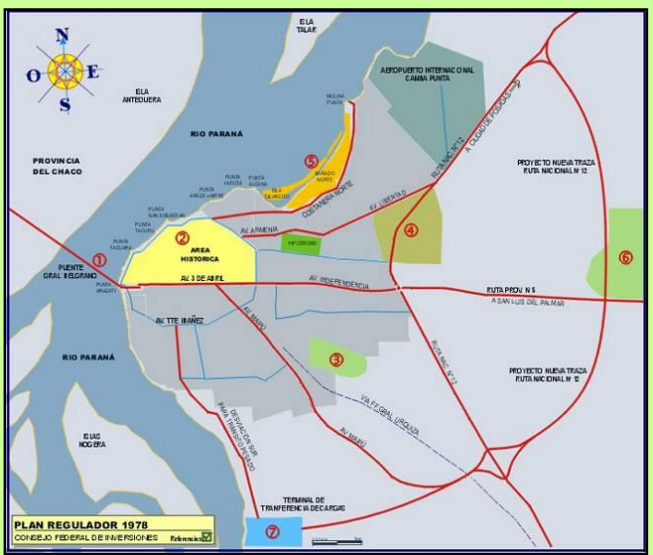

Lineamientos estratégicos de base territorial (2008)

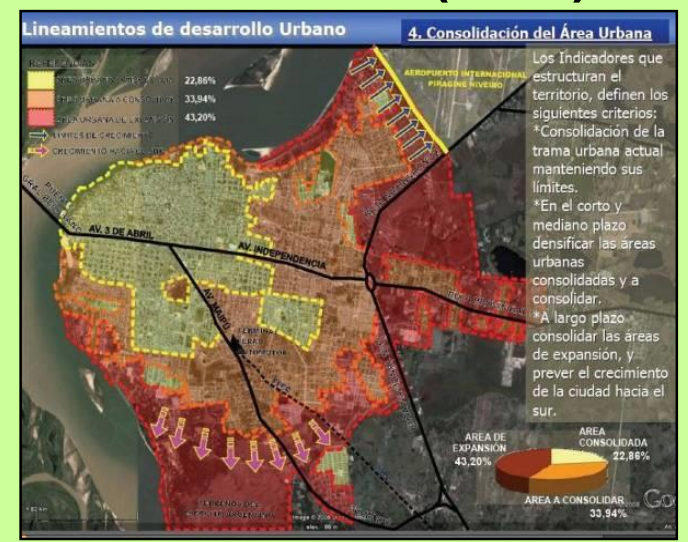

Publicado en formato digital: Prof. Aníbal Marcelo Mignone. EXPANSIÓN URBANA EN CIUDADES DE LA REGIÓN DEL NORDESTE ARGENTINO. Revista Geográfica Digital. IGUNNE. Facultad de Humanidades. UNNE. Año 14. № 27. Enero - Junio 2017. Resistencia, Chaco. En: 


\section{Gran Posadas}

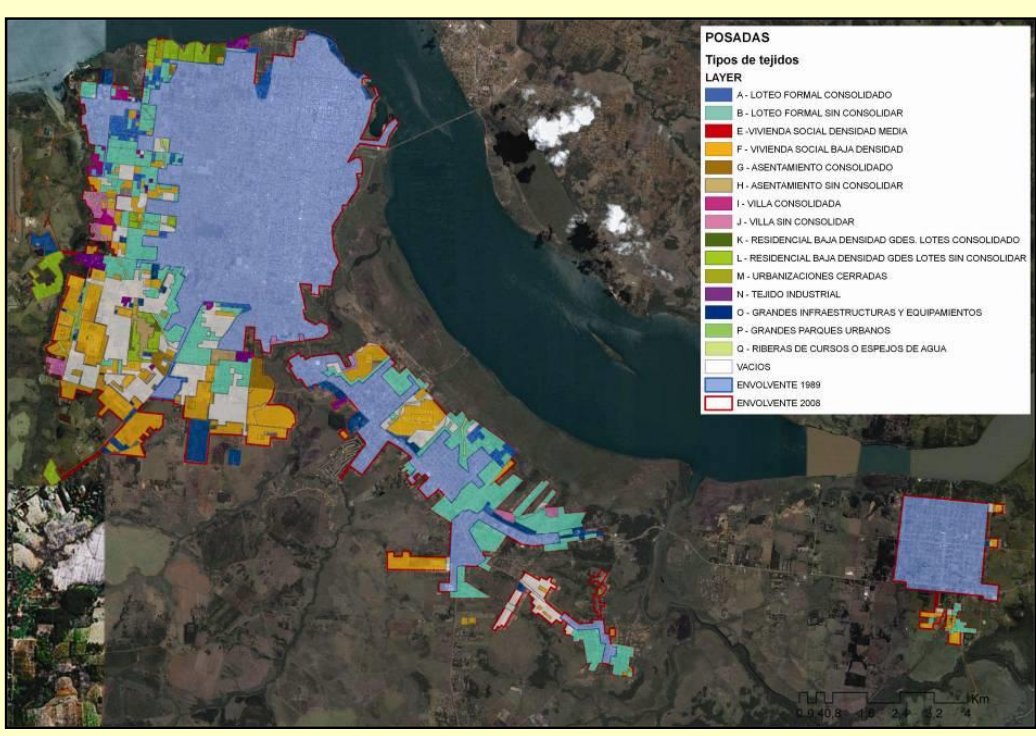

Fuente: Argentina Urbana 2011

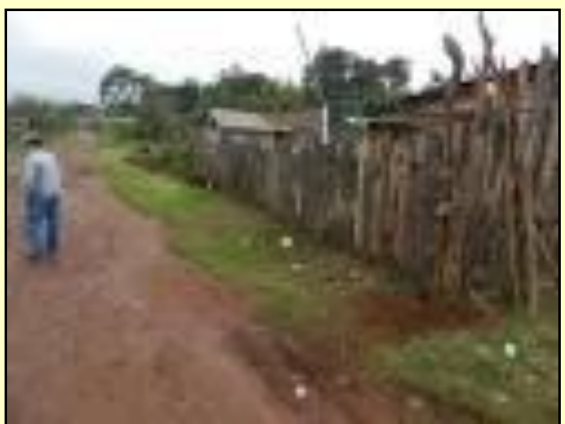

- Las políticas habitacionales impulsaron el crecimiento hacia el oeste y sudoeste de Posadas provocando una concentración de los barrios pobres alrededor de los nuevos complejos habitacionales.

- La expansión urbana acelerada trajo problemas de conectividad vial y transporte público especialmente para las zonas alejadas del centro, y al mismo tiempo aumentó la concentración de flujos circulatorios.

- El transporte urbano no cubre las necesidades de los barrios periféricos emergentes en cuanto a movilidad, frecuencias y calidad de servicio. 


\section{Formosa}

- La presencia de grandes espacios en
área aledañas a la ciudad, ha llevado a
la especulación en el precio de los
terrenos, lo que generó la realización
de loteos lejos del sector central y
permitió la creación de barrios
organizados mediante los planes de
vivienda, que dieron lugar a un
crecimiento discontinuo y
desorganizado (Foschiatti, 2003).
- En el impulso por generar mayor
cantidad de viviendas, fueron
quedando amplias fracciones de
espacios intermedios que
incrementaron su valuación y no todos
fueron ocupados legalmente.
- La ciudad no cuenta con barrios
privados reconocidos legalmente por el
municipio capitalino.
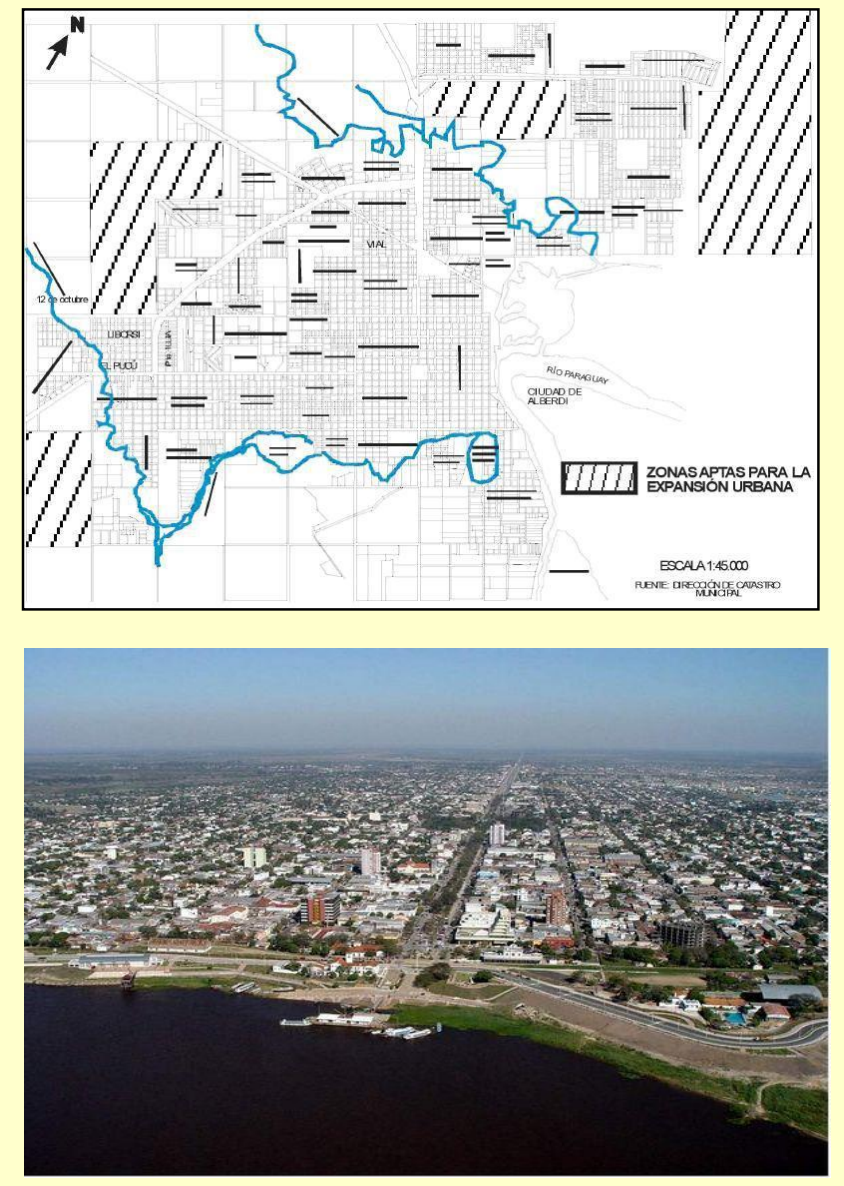

Fuente: Kalaffatich, 2007

Publicado en formato digital: Prof. Aníbal Marcelo Mignone. EXPANSIÓN URBANA EN CIUDADES DE LA REGIÓN DEL NORDESTE ARGENTINO. Revista Geográfica Digital. IGUNNE. Facultad de Humanidades. UNNE. Año 14. № 27. Enero - Junio 2017. Resistencia, Chaco. En: 


\section{EI MERCADO DE SUELOS EN EL NEA}

- Altos precios del suelo urbanizado.

- Convivencia e interrelación de mercados formales e informales.

- Incapacidad estructural del mercado para proveer suficiente oferta de suelo servido a precios accesibles.

- Ausencia o desactualización de los catastros.

\section{EL PRECIO DEL SUELO EN LAS CIUDADES}

- Adquieren un mayor valor monetario si cuentan con una urbanización completa.

- La especulación inmobiliaria eleva el precio de la tierra, entonces el territorio se transforma en la disputa de las empresas.

- La regularización de los terrenos puede darse a cambio de favores.

- La renta del trabajador determinará el acceso o no al espacio urbano. 


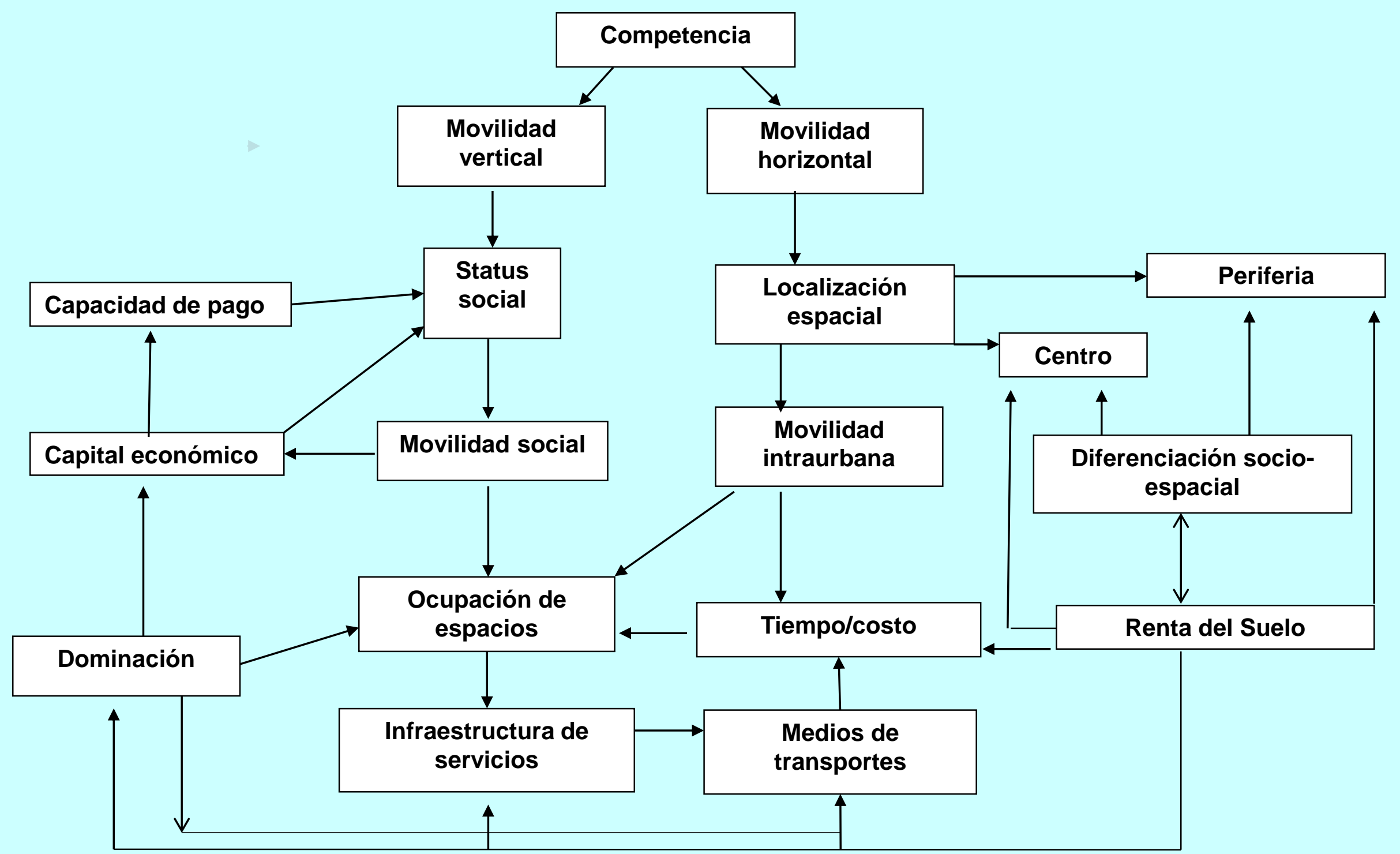

Fuente: Elaboración propia de acuerdo con Borsdorf, 2003

Publicado en formato digital: Prof. Aníbal Marcelo Mignone. EXPANSIÓN URBANA EN CIUDADES DE LA REGIÓN DEL NORDESTE ARGENTINO. Revista Geográfica Digital. IGUNNE. Facultad de Humanidades. UNNE. Año 14. № 27. Enero - Junio 2017. Resistencia, Chaco. En: 
- El problema no es la disponibilidad de SUELO, sino la disponibilidad de suelo URBANIZADO, es decir con los servicios e infraestructuras básicas que permitan un desarrollo integrado de la ciudad.

- Articular las diferentes lógicas de los actores involucrados en los procesos de expansión urbana.

* La lógica del MERCADO

* La lógica de los sectores sociales mas desfavorecidos y excluidos.

* La lógica del Estado (Municipio, Provincia, Nación) quien tiene a su cargo la gestión y administración urbana.

- Las áreas fundamentales concernientes a la acción del estado en los procesos de expansión urbana son:

* La instrumentación de políticas fiscales

* La regulación

* La provisión de infraestructuras y servicios 


\section{Bibliografía}

•Alberto, Jorge y Valeria Schneider. 2008. "Exploración de métodos de simulación de fenómenos complejos aplicados al análisis espacial. Estudio de caso Gran Resistencia Chaco". Segundo Seminario sobre Políticas Urbanas, Gestión Territorial y Ambiental para el Desarrollo Local. FAU, UNNE. Resistencia, 10 de junio de 2008.

-Alberto, Juan. 2009. "Geografía, Crecimiento Urbano, Ambientes, Paisajes y Problemas. El Área Metropolitana del Gran Resistencia (A.M.G.R.)". En: XII Encuentro de Geográfos de América Latina. 3 a 7 de abril de 2009. Montevideo, Uruguay.

•Alcalá Pallini, Laura. 2007. "Dimensiones urbanas del problema habitacional. El caso de la ciudad de Resistencia, Argentina". En: REVISTA INVI № 59. Mayo 2007 / VOLUMEN 22: 35 A 68. Mendoza, Argentina

•Barreto, Miguel y Lorena Sánchez. 2000. "El crecimiento de las ciudades intermedias del noreste argentino en el contexto de las transformaciones regionales". En: Seminario El rol de las ciudades intermedias iberoamericanas. Facultad de Arquitectura y Urbanismo, UNNE. Versión en CD-Rom.

•Barreto, Miguel. 2002. "El crecimiento urbano de las ciudades intermedias del NE argentino en el contexto de las transformaciones regionales". En Cuaderno Urbano № 3. Facultad de Arquitectura y Urbanismo, UNNE..

•Borsdorf, Axel. 2003. "La segregación socio-espacial en ciudades latinoamericanas: el fenómeno, los motivos y las consecuencias para un modelo del desarrollo urbano en América Latina". En: Transformaciones regionales y urbanas en Europa y en América Latina. Publicaciones de la Universidad de Barcelona, Barcelona, España.

-Clichevsky, Nora. 1999. Tierra vacante en Buenos Aires: entre "loteos populares" y "las áreas exclusivas". International Seminar on Vacant Land: Challenges and Opportunities. Río de Janeiro, Brasil. 26 a 30 de abril de 1999

- Coccato, Marcelo Andrés. 2007. Expansión urbana, disponibilidad de suelo y asentamientos informales: corredores ferroviarios en el Gran Resistencia. Ponencia presentada en el Seminario sobre Políticas Urbanas, Gestión Territorial y Ambiental para el Desarrollo Local, IPUR, FAU-UNNE. Julio de 2007.

-Foschiatti, Ana María. 2003. La población del nordeste argentino. Universidad Nacional del Nordeste, Resistencia.

•Kalafattich, Santiago. 2007. "Los barrios de la ciudad de Formosa con relación a la evolución del plano catastral". En: GEOUSAL, Revista Científica de Geografía. Universidad del Salvador, Santa Fe. Año II Nro. 2 Agosto 2007. En Internet: http://www.salvador.edu.ar/geousal/dos/trabajo\%20kalafattich.pdf.

-Mignone, Aníbal M. 2005. "Las condiciones de movilidad territorial en la población de los asentamientos espontáneos del 2000, en el Gran Resistencia". En: XXIV Encuentro de Geohistoria Regional y $\mathbf{2}^{\circ}$ Simposio sobre el estado actual del conocimiento antropológico del Gran Chaco Meridional. 9 a 11 de septiembre de 2004. Instituto de Investigaciones GeohistóricasConicet, Resistencia. 391- 401.

-Mignone, Aníbal M. 2010. Análisis cuantitativo de la segregación por pobreza en las capitales del Nordeste argentino. Actas XXX Encuentro de Geohistoria Regional. Resistencia, Chaco. 24 a 26 de junio de 2010

-Mignone, Aníbal. 2002. Década del '90: los asentamientos espontáneos en el crecimiento de Resistencia. XX Encuentro de Geohistoria Regional. Instituto de Investigaciones GeohistóricasConicet, Resistencia. Volumen II: 639-654.

-Mignone, Aníbal. 2004. "La movilidad territorial desde la perspectiva de la población instalada en asentamientos espontáneos en el Gran Resistencia, a principios del siglo XXI". En: VII Jornada Argentina de Estudios de la Población (AEPA). Tafí del Valle, Tucumán, Argentina. 315-328.

-Ministerio de Planificación Federal, Inversión Pública y Servicios. 2011 Plan Estratégico Territorial Avance II: Argentina Urbana. 1ํㅡㄹición, Buenos Aires.

-Molinas, Fabio. 2007. Más de la mitad de Resistencia sin servicio de cloacas. Diario Norte, 26 de agosto de 2007. Resistencia, Chaco.

-Municipalidad de Posadas. 2008. Plan Urbano Ambiental 2012.

-Municipalidad de Posadas. 2008. Planificación estratégica territorial.

-Plan de Diagnóstico Urbano de la ciudad de Corrientes. 1988.

- Reese, Eduardo. 1997. Políticas públicas. Normativas y mercados de suelo. Seminario Internacional: Manejo de suelo urbano. INVICO y Lincoln Institue of Land Policy. Corrientes.

-Valenzuela de Mari, Cristina. 1991. Los Problemas de la Expansión Urbana y Demográfica de la ciudad de Resistencia, desde la Perspectiva Geográfica a partir de 1960. Cuadernos de Geohistoria Regional № 23. Instituto de Investigaciones Geohistóricas, CONICET, Resistencia.

•Valenzuela de Mari. Cristina. 2000. "Modalidades de expansión en ciudades intermedias argentinas. Urbanización planificada y espontánea en el Gran Resistencia. 1970-1998". Revista de Geografía Norte Grande, № 26. Instituto de Geografía de la Pontificia Universidad Católica de Chile. Santiago de Chile, Chile.

-Vapñarsky, César A. y Néstor Gorojovsky. 1990. El crecimiento urbano en la Argentina. Instituto Internacional del Medio Ambiente y Desarrollo. Buenos Aires. Grupo Editor Latinoamericano.

Publicado en formato digital: Prof. Aníbal Marcelo Mignone. EXPANSIÓN URBANA EN CIUDADES DE LA REGIÓN DEL NORDESTE ARGENTINO. Revista Geográfica Digital. IGUNNE. Facultad de Humanidades. UNNE. Año 14. № 27. Enero - Junio 2017. Resistencia, Chaco. En:

http://hum.unne.edu.ar/revistas/geoweb/default.htm 